\title{
An analysis of the demographic profile, clinical manifestations, investigations and outcome of paediatric myelodysplastic syndrome: A single centre, cross-sectional study
}

\author{
Appaji Lingegowda ${ }^{1}$, Lakshmaiah Kuntegowdenahalli ${ }^{2}$, Ashok Komaranchath ${ }^{2}$, Lakshmi Devi ${ }^{3}$, \\ Prasanna Kumari ${ }^{3}$, Mangesh Kamath ${ }^{2}$ \\ ${ }^{I}$ Department of Pediatric Oncology, Kidwai Memorial Institute of Oncology, Bangalore, India \\ ${ }^{2}$ Department of Medical Oncology, Kidwai Memorial Institute of Oncology, Bangalore, India \\ ${ }^{3}$ Department of Pathology, Kidwai Memorial Institute of Oncology, Bangalore, India
}

Received February 19, 2015; Revised March 10, 2015; Accepted April 05, 2015; Published Online June 04, 2015

\section{Original Article}

\begin{abstract}
Purpose: Pediatric myelodysplastic syndrome (MDS) is a relatively rare entity, with distinct clinical features and more aggressive course than its adult counterpart. The aim of this study was to analyze the incidence of pediatric myelodysplastic syndrome at a tertiary cancer care center in southern India along with clinical manifestations, investigations and outcome. Methods: On retrospective analysis of 1094 cases of pediatric hematological malignancies over a five-year period from September 2009 to August 2014, a total of seven cases of pediatric myelodysplastic syndrome were identified. Presenting complaints, physical examination, investigations including haemogram, biochemistry, bone marrow examination and cytogenetics were reviewed. The diagnosis of MDS was made if there was dysplasia in at least $10 \%$ of cells in two or more cell lineages. All patients were risk stratified using the revised IPSS. Results: Out of 1094 cases of pediatric hematological malignancies presenting at our institute within the study period, there were only seven cases of pediatric MDS with an incidence of $0.65 \%$. There were no genetic predispositions nor any cases of therapy related MDS. The most common presentation was with fever and all patients had significant splenomegaly. All patients had anemia (Median-6.2 gm / dL) with elevated WBC counts (Median-30,900 / uL) and thrombocytopenia (Median-50,000 / uL). The marrow cytogenetics was normal in five patients. Most patients fell into the high and very high-risk category of the revised IPSS, with only two patients of low risk. All seven patients were given only supportive care but one progressed to AML for which he was treated with remission induction. Only two patients were alive at the time of analysis and median survival was 9 months. Conclusion: Pediatric MDS is a rare disease with a short clinical history, aggressive course and generally poor outcomes as compared to the adult variant. A hematopoietic stem cell transplant may be the only viable option for survival.
\end{abstract}

Keywords: Pediatric Myelodysplastic Syndrome; MDS

\section{Introduction}

The myelodysplastic syndrome (MDS) represents a heterogeneous group of stem cell malignancies characterized by dysplastic and ineffective hematopoiesis and a variable risk of transformation to acute leukemia. Myelodysplastic syndrome in the pediatric age group is uncommon and constitutes a distinct entity different in many ways from adult MDS. They have certain unique clinical features, a more aggressive clinical course with a shorter overall survival. Epidemiological data for pediatric MDS is limited not only because it is relatively rare, but also because of the difficulty in diagnosis as well as classification. However, there have been several case series of pediatric MDS reported. ${ }^{1-9}$ The largest series was from Japan by Sasake et al. who submitted a retrospective analysis of 189 patients of MDS less than 16 years of age from sixty-two centers in Japan over a period of 7 years. There has been only one such study from India, by Chatterjee et al. where 21 patients with MDS from northern India aged less than 17 years were evaluated. ${ }^{10}$ Compared to this study, the median age of presentation was lower in our institution (4 years vs. 9 years). All patients presented with pallor and a majority had fever and bleeding diathesis. The overall survival was dismal and the best prognosis appeared to be for those with refractory cytopenias with a low blast count. We have classified our patients on the basis of both the type of MDS as well as the revised IPSS scoring system. 
Consensus on the treatment of pediatric MDS is also uncertain, with allogenic stem cell transplant the only chance of cure. Chemotherapy is reserved for patients in more advanced stage of the disease. The newer hypomethylating agents used in adult MDS have not yet been approved in pediatric MDS. Here, we present our institution's experience with pediatric MDS, where we had seven cases over a five-year period from September 2009 to August 2014. We have analyzed their demographic profile, presenting features, clinical findings, investigative reports, treatment and outcome.

\section{Methods and Materials}

On retrospective analysis of 1094 cases of pediatric hematological malignancies over a five year period from September 2009 to August 2014, a total of seven cases of pediatric myelodysplastic syndrome were identified of which there were 4 boys and 3 girls with a median age of 4 years. Presenting complaints, physical examination, investigations including haemogram, biochemistry, bone marrow examination and cytogenetics were analyzed. The patients were classified according to the pediatric adaptation of the $2008 \mathrm{WHO}$ classification of myelodysplastic syndromes. Four patients were classified as RAEB of which one patient progressed to RAEB-T and finally to acute myeloid leukemia. He had a total WBC count $>100,000 / \mathrm{uL}, 13 \%$ blasts in bone marrow at presentation, Trisomy 8 on karyotyping and R-IPSS score of 6.5 (very high). The other three patients were classified as RCC. There were no predisposing syndromes nor any cases of therapy related MDS. All patients were risk stratified using the revised IPSS. All patients had fever and splenomegaly on presentation, and only one patient presented with bleeding diathesis. Anemia and thrombocytopenia were present in all patients and all except two patients had normal cytogenetics. Treatment was mainly supportive. The one patient who progressed to RAEB-T was treated with a standard $7+3$ remission induction protocol, but failed to achieve remission and progressed to acute myeloid leukemia with $90 \%$ blasts in peripheral blood. Outcome was measured by calculating median overall survival.

\section{Results}

A total of seven patients were identified with pediatric myelodysplastic syndrome. On comparison, this constituted only around $0.65 \%$ of all pediatric hematological malignancies at our institute.

\section{Patient profiles}

There were four boys and three girls with ages ranging from 2 years to 14 years with a median age of 4 years. There were 4 patients classified as RAEB and 3 as Refractory Cytopenia of childhood (RCC) as per the Revised WHO Classification of Childhood Myelodysplastic Syndromes (2008). There were no constitutional predispositions like Down's syndrome,
Fanconi's anemia, Pearson's syndrome, etc. There were no cases of therapy related MDS either.

\section{Clinical presentation}

All seven patients had fever as a presenting complaint, three had abdominal pain and distension, one presented with bleeding from the gums and one had recurrent vomiting. The median duration of symptoms were 21 days with a range of 10 to 60 days. All patients except one had a performance status $</=2$. Six of the patients had clinical pallor and two patients had palpable lymphadenopathy. All seven patients had palpable splenomegaly and a mean spleen size of $3.8 \mathrm{~cm}$ under the left costal margin. Three of these patients also had palpable hepatomegaly. (Chart 1)

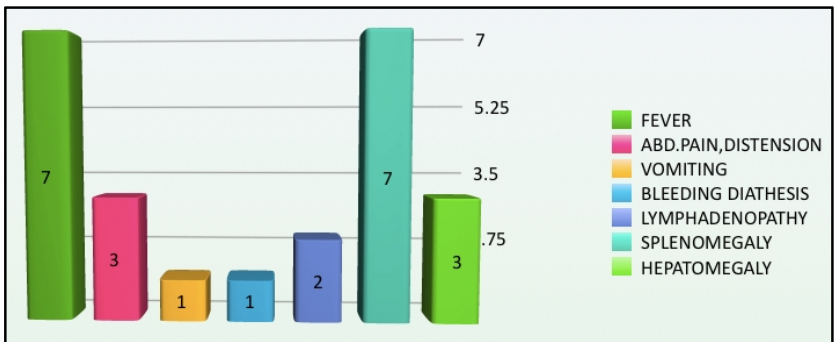

CHART 1: Presenting complaints (No. of patients with the mentioned presenting complaint).

\section{Investigations}

Six of the patients had a hemoglobin of less than $10 \mathrm{~g} / \mathrm{dl}$ and mean hemoglobin was $7.2 \mathrm{~g} / \mathrm{dl}$. Total WBC count was also elevated in most cases with a median count of 30900/uL. Platelet counts were also low, ranging from 12000/uL to $128,000 / \mathrm{uL}$ with a median value of 50000/uL. Renal and liver function tests were normal in all seven cases. There were bone marrow blasts ranging from $6 \%$ to $15 \%$ at presentation in four cases and $<1 \%$ blasts in the other three. Another finding that suggested a high burden of disease was a high LDH value, which was seen in all seven cases ranging from $392-2780 \mathrm{IU} / \mathrm{L}$ with a mean value of $1238 \mathrm{IU} / \mathrm{L}$. (Table 1)

\section{Cytogenetics}

Bone marrow cytogenetics were done on all seven patients and showed a normal karyotype in five patients. One patient had trisomy 8 and another had monosomy 7 (Chart 2). There were no complex cytogenetic abnormalities.

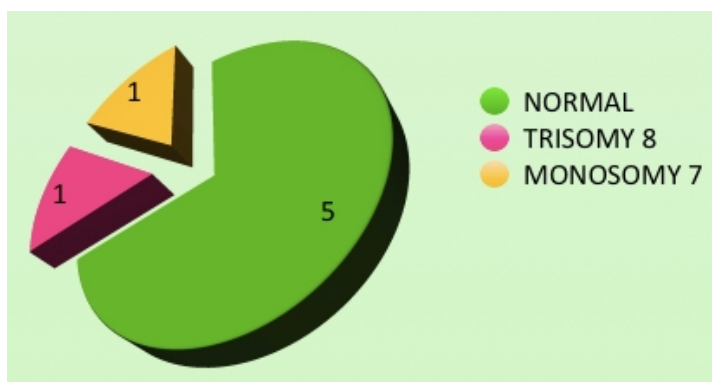

CHART 2: Cytogenetics (No. of patients with the mentioned cytogenetic abnormality). 
TABLE 1: Patient characteristics.

\begin{tabular}{ccccccccc}
\hline \hline $\begin{array}{c}\text { Sl. } \\
\text { No. }\end{array}$ & $\begin{array}{c}\text { Age } \\
\text { /Sex }\end{array}$ & Hb. & TLC & PLT & $\begin{array}{c}\text { BM } \\
\text { Blasts(\%) }\end{array}$ & LDH & Cytogenetics & Classification \\
\hline 1 & $5 / \mathrm{F}$ & 8.3 & 6000 & 50000 & 6 & 1050 & Monosomy 7 & RAEB \\
2 & $13 / \mathrm{M}$ & 5.9 & 30900 & 27000 & $<2$ & 1090 & Normal & RCC \\
3 & $14 / \mathrm{M}$ & 6.2 & 2500 & 128000 & $<2$ & 2780 & Normal & RCC \\
4 & $4 / \mathrm{M}$ & 9.8 & $>100000$ & 60000 & 13 & 1103 & Trisomy 8 & RAEB \\
5 & $2 / \mathrm{F}$ & 3.6 & 34900 & 26000 & 15 & 1300 & Normal & RAEB \\
6 & $3 / \mathrm{F}$ & 6.1 & $>100000$ & 124000 & $<2$ & 392 & Normal & RCC \\
7 & $3 / \mathrm{M}$ & 10.8 & 22700 & 12000 & 12 & 950 & Normal & RAEB \\
\hline \hline
\end{tabular}

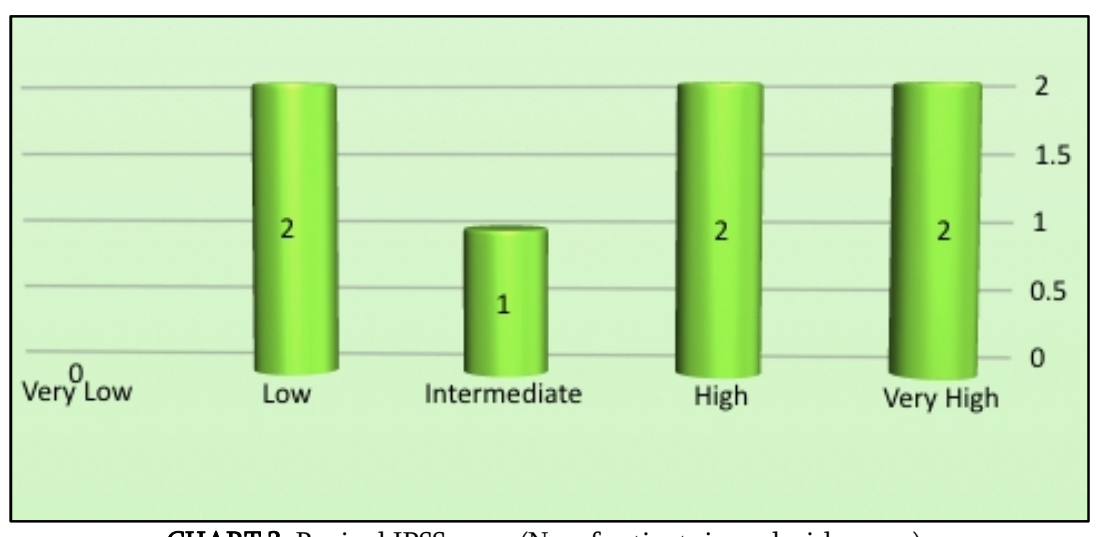

CHART 3: Revised IPSS score (No. of patients in each risk group).

\section{Risk stratification}

Risk stratification was done using the revised IPSS, which takes into account cytogenetics, bone marrow blast percentage, hemoglobin, platelet count and absolute neutrophil count at the time of presentation. The median R-IPSS score was 5.0 (high risk), with 2 very high, 2 high, 1 intermediate and 2 low risk groups (Chart 3 ).

\section{Outcome}

None of the patients were willing for either intensive chemotherapy or stem cell transplant initially and were started on best supportive care with repeated transfusion of blood products, antibiotics and other measures. Out of the seven patients, one progressed on follow-up to acute leukemia with more than $20 \%$ blasts and was given remission induction chemotherapy with a standard $7+3$ protocol with Cytarabine and daunorubicin. The patient however, failed to achieve remission with the same and was continued on best supportive care as he was not affordable for high dose chemotherapy and stem cell transplant.

On follow up of the patients, the survival ranged from 1-49 months with a median survival on 9 months. Five of the seven patients died due to various complications. One patient died from pneumonia, four from bleeding diathesis, out of which one was the patient who had progressed to AML and had received remission induction. Two of our patients were alive at the end of the study period, of which one had survived for 49 months. Of note is that this patient presented with normal leucocyte counts, platelet count of more than
$100,000 / \mathrm{uL}$, occasional bone marrow blasts, normal cytogenetics and had the lowest R-IPSS score of 2.5 among all the patients. He is also transfusion free for the past 2 years.

\section{Discussion}

Although myelodysplastic syndrome is predominantly a disease of the elderly, there has been several case series describing this disease in children. In general, MDS is an uncommon disease with an incidence ranging from 4.1 per $100,000{ }^{11}$ to 1.24 per 100,000 in recent series ${ }^{12}$. The incidence is considerably lower in children with Hasle et al. describing it as 3.4 in 1,000,000 in children less than 15 years of age. ${ }^{2}$ A population based survey from Denmark had similar values of incidence which set the number of pediatric MDS at around 2-3\% of all pediatric hematological malignancies. ${ }^{2,} 13$ There have been no epidemiological studies for childhood MDS in southern India. Acute leukemias account for approximately $35-45 \%$ of the almost 50,000 childhood malignancies in India ${ }^{14}$ and in our center, out of the 1094 cases of pediatric hematological malignancies over the past 5 years, we have seen only seven cases of childhood MDS with an incidence of $0.65 \%$. This incidence appears to be much lower than that seen in most western countries and we believe it may be due to both misdiagnoses and possibility of late presentation of several cases as frank AML. Almost 60\% of our patients presented in an advanced stage of disease with excess blasts and a high R-IPSS score (Median of 5.0). They also appeared to have a higher burden of disease with high LDH levels and all patients had anemia and thrombocytopenia. Marrow cytogenetic analysis showed normal cy- 
togenetics in five patients and only two patients showing cytogenetic abnormalities.

Due to financial constraints, none of our patients could afford stem cell transplants and only one was treated aggressively because of progression of disease. As per the EWOG-MDS 98 study by Strahm et al. the 3-year disease free survival of hematopoietic stem cell transplant is around $50 \% .{ }^{15}$ The one patient who received chemotherapy did not achieve remission and eventually succumbed to the disease.
In a trial comparing the outcome of chemotherapy in MDS versus acute myeloid leukemia, less than $30 \%$ of pediatric MDS patients survived for more than 3 years. ${ }^{16}$ The overall survival was dismal, with a median OS of only 9 months.

In view of the several differences between pediatric and adult MDS (Table 2) ${ }^{17}$, the WHO classification, which was developed based on adult cases, is considered inadequate for classifying pediatric MDS.

TABLE 2: Differences between adult and pediatric MDS. ${ }^{17}$

\begin{tabular}{|c|c|c|}
\hline FEATURE & ADULT MDS & PEDIATRIC MDS \\
\hline Refractory Anemia (RA) - Anemia & Always Present & Not always present (44\% can have Hb levels $>10 \mathrm{~g} / \mathrm{dL})$ \\
\hline RA-Significant dyserythropoiesis & Always present & May be subtle and overlooked \\
\hline RA-Course & $\begin{array}{l}\text { Protracted (Median } \\
\text { survival } 66 \text { months) }\end{array}$ & $\begin{array}{l}\text { Transformation to AML or more aggressive form of MDS occurs } \\
\text { with short lag time }\end{array}$ \\
\hline $\begin{array}{l}\text { Refractory anemia with ringed } \\
\text { sideroblasts }\end{array}$ & Constitutes $10-12 \%$ of cases & Exceedingly rare \\
\hline $\begin{array}{l}\text { MDS assoc. with isolated } 5 q \\
\text { deletion }\end{array}$ & $\begin{array}{l}\text { Occurs predominantly in } \\
\text { middle age to older women }\end{array}$ & Not described \\
\hline Constitutional abnormalities & Rare & Often observed \\
\hline Incidence & More common & Rare \\
\hline \multicolumn{3}{|l|}{ Clinical Features } \\
\hline Symptoms (a) & Majority are asymptomatic & Majority symptomatic \\
\hline Signs (b) & & Hepatosplenomegaly and granulocytic sarcoma more prevalent \\
\hline Prognosis & Relatively good to poor & Poor even in RA \\
\hline Role of IPSS for predicting & Significant role & Only cytogenetic pattern is of prognostic value \\
\hline \multicolumn{3}{|l|}{ Cytogenetics } \\
\hline Most conspicuous difference & $\begin{array}{l}\text { Constitutional genetic } \\
\text { abnormalities rare }\end{array}$ & $35 \%$ carry constitutional genetic abnormalities \\
\hline Monosomy 7 & Noted in $<5 \%$ of Adult RA & $\begin{array}{l}\text { Most common cytogenetic abnormality in refractory cytopenias } \\
\text { of children }\end{array}$ \\
\hline$-5,-5 q,-Y$ & Commonly present & Common \\
\hline$-7 q,+8($ trisomy 8$)$ & Rare & Commonest abnormalities are monosomy 7 and trisomy 8 \\
\hline
\end{tabular}

TABLE 3: Pediatric adaptation of the 2008 WHO classification. ${ }^{19}$

\begin{tabular}{|c|c|c|}
\hline Myelodysplastic syndromes & Myelodysplastic/myeloproliferative disease & Down syndrome disease \\
\hline $\begin{array}{l}\text { Refractory cytopenias (Blood blasts }<2 \% \text {, bone marrow } \\
\text { blasts }<5 \% \text { ). } \\
\text { Refractory anemia with excessive blasts (Blood blasts } \\
<2 \% \text {, bone marrow blasts }<5 \%-19 \% \text { ). } \\
\text { Refractory anemia with excess blasts in transformation } \\
\text { (Bone marrow blasts } 20-29 \% \text { ) or Acute myelogenous } \\
\text { leukemia with MDS-related changes (Peripheral blood } \\
\text { or marrow blasts }>20 \% \text { ). }\end{array}$ & Juvenile myelomonocytic leukemia & $\begin{array}{l}\text { Transient abnormal myelopoiesis } \\
\text { Myeloid leukemia of Down Syn- } \\
\text { drome }\end{array}$ \\
\hline
\end{tabular}

To overcome this, Hasle et al. had proposed a pediatric approach to the WHO classification, which emphasizes the subtypes found in pediatric age group and deleting some of the adult subtypes, which are rare or unseen in the pediatric population. The WHO pediatric modification was first proposed in $2003{ }^{18}$ and later modified in 2008. Presently, the pediatric WHO adaptation defined in 2008 (Table 3$)^{19}$ is being used worldwide and applies to more than $99 \%$ of all childhood MPD cases.
In the revised WHO (2008) classification, the MDSs were further subdivided into refractory cytopenia, refractory anemia with excess blasts (RAEB), and refractory anemia with excess blasts in transformation (RAEB-t) and has a separate section on childhood MDS, where JMML and ML-DS are distinct disorders. This update also defines the criteria for defining refractory cytopenia of childhood (RCC). Children with $<2 \%$ blasts in blood, $<5 \%$ blasts in the bone marrow, and persistent cytopenias associated with dysplasia in at least two cell lines are included in this group. Treatment of adult 
MDS with hypomethylating agents have shown great promise, but these agents are yet to be tried in the pediatric setting. Considering the poor prognosis in children trials with these newer agents may be warranted.

\section{Conclusion}

Even though myelodysplastic syndrome is rare in childhood, the diagnosis must be kept in mind when children present with refractory cytopenias and a short symptom duration. Pediatric MDS is very different from that of the adult variant in presentation, clinical features, cytogenetics and survival. The age of presentation was lower than that found by Chatterjee et al. in northern India. They present with a shorter history and are more likely to have multilineage dysplasia. In our series, there were only 2 patients with cytogenetic abnormalities with all others having normal karyotypes. The clinical course is more aggressive and they tend to have shorter survivals as compared to adult MDS. Hence, early diagnosis and management is essential. Median survival in our series was similar to that of western data which showed a median survival of 9 months. Outcome with supportive care alone is dismal. A hematopoietic stem cell transplant may be the only viable option and should be performed early in the course of disease. The use of hypomethylating agents in pediatric MDS needs to be evaluated further.

\section{Conflict of interest}

The authors declare that they have no conflicts of interest. The authors alone are responsible for the content and writing of the paper.

\section{References}

1. Sasaki H, Manabe A, Kojima S, et al. Myelodysplastic syndrome in childhood: a retrospective study of 189 patients in Japan. Leukemia 2001;15:1713-20.

2. Hasle H, Jacobsen BB, Pedersen NT. Myelodysplastic syndromes in childhood: a population based study of nine cases. Br J Haematol 1992;81:495-8.

3. Tuncer MA, Pagliuca A, Hicsonmez G, et al. Primary myelodysplastic syndrome in children: the clinical experience in 33 cases. Br J Haematol 1992;82:347-53.

4. Creutzig U, Cantù-Rajnoldi A, Ritter J, et al. Myelodysplastic syndromes in childhood. Report of 21 patients from Italy and West Germany. Am J Pediatr Hematol Oncol 1987;9:324-30.

5. Hasle H, Kerndrup G, Jacobsen BB. Childhood myelodysplastic syndrome in Denmark: incidence and predisposing conditions. Leukemia 1995;9:1569-72.

6. Bader-Meunier B, Mielot F, Tchernia G, et al. Myelodysplastic syndrome in childhood: report of
49 patients from a French multicentre study. Br J Haematol 1996; 92:344-50.

7. Luna-Fineman S, Shannon KM, Atwater SK, et al. Myelodysplastic and myeloproliferative disorders of childhood: a study of 167 patients. Blood 1999; 93:459-66.

8. Passmore SJ, Hann IM, Stiller CA, et al. Pediatric myelodysplasia: a study of 68 children and a new prognostic scoring system. Blood 1995;85:1742-50.

9. Hasle H, Wadsworth LD, Massing BG, et al. A population-based study of childhood myelodysplastic syndrome in British Columbia, Canada. Br J Haematol 1999; 106: 1027-32.

10. Aul C, Gattermann N, Schneider W. Age-related incidence and other epidemiological aspects of myelodysplastic syndromes. Br J Haematol 1992; 82:358-67.

11. Chatterjee T, Mahapatra M, Dixit A, et al. Primary myelodysplastic syndrome in children--clinical, hematological and histomorphological profile from a tertiary care center in India. Hematology 2005; 10:495-9.

12. Sant M, Allemani C, Tereanu C, et al. Incidence of hematological malignancies in Europe by morphologic subtype: Results of the HAEMACARE project. Blood 2010; 116: 3724-34.

13. Hasle H, Kerndrup G, Jacobsen BB. Childhood myelodysplastic syndrome in Denmark: incidence and predisposing conditions. Leukemia 1995;9:1569-72.

14. Three year report of the population based cancer registries 2009-2011: Report of 25 PBCRs; National Cancer Registry Programme, Indian Council Medical Research, Bangalore 2013.

15. Strahm B, Nollke P, Zecca M, et al. Hematopoietic stem cell transplantation for advanced myelodysplastic syndrome in children: results of the EWOG-MDS 98 study. Leukemia 2011;25:455-62.

16. Hasle H, Kerndrup G, Yssing M, et al. Intensive chemotherapy in childhood myelodysplastic syndrome. A comparison with results in acute myeloid leukemia. Leukemia 1996; 10:1269- 73.

17. Tilak V, Sookmane DD, Gupta V, Shukla J. Myelodysplastic syndrome. Indian J Pediatr 2008; 75:729-32.

18. Hasle H, Niemeyer CM, Chessells JM, et al. A pediatric approach to the WHO classification of myelodysplastic and myeloproliferative diseases. Leukemia 2003;17:277-82.

19. Swerdlow SH, Campo E, Harris NL, et al. WHO Classification of Tumours of Hematopoietic and Lymphoid Tissues, $4^{\text {th }}$ ed. Lyon, France: IARC Press; 2008; 2. 